\title{
Control the Morphologies and the Pore Architectures of Mesoporous Silicas through a Dual-Templating Approach
}

\author{
Hairui Wang, Hao Chen, Zhen Xu, Sibing Wang, Baozong Li, and Yi Li \\ Key Laboratory of Organic Synthesis of Jiangsu Province, College of Chemistry, Chemical Engineering and Materials Science, \\ Soochow University, Suzhou 215123, China \\ Correspondence should be addressed to Yi Li, liyi@suda.edu.cn
}

Received 11 October 2011; Accepted 12 November 2011

Academic Editor: Ugur Serincan

Copyright ( 92012 Hairui Wang et al. This is an open access article distributed under the Creative Commons Attribution License, which permits unrestricted use, distribution, and reproduction in any medium, provided the original work is properly cited.

Mesoporous silica nanospheres were prepared using a chiral cationic low-molecular-weight amphiphile and organic solvents such as toluene, cyclohexane, and tetrachlorocarbon through a dual-templating approach. X-ray diffraction, nitrogen sorption, field emission scanning electron microscopy, and transmission electron microscopy techniques have been used to characterize the mesoporous silicas. The volume ratio of toluene to water plays an important role in controlling the morphologies and the pore architectures of the mesoporous silicas. It was also found that mesoporous silica nanoflakes can be prepared by adding tetrahydrofuran to the reaction mixtures.

\section{Introduction}

It has been two decades since the discovery of ordered mesoporous silica materials [1]. Recent reports are focused on the precise control of the pore size, accessibility, stability, morphologies, and surface functionalization of the mesoporous silicas, due to their versatile applications in chemical separation, catalysis, photonic devices, biosensors, and drug delivery [2]. Mesoporous silicas were usually prepared through a sol-gel approach using the organic selfassemblies of surfactants [3], lipid [4], low-molecular-weight gelators [5], or block copolymers [6] as template. Since these templates can self-assemble into varieties of nanostructures, the obtained silicas exhibit many kinds of nanostructures such as films [7, 8], spheres [9], fibers [10], tubes [11], and ribbons [12]. As the organization of the templates is sensitive to the surrounding conditions such as temperature, concentration, and solvents, varieties of silica nanostructures can be prepared only using single template, and the morphologies and pore architectures of mesoporous silicas are controllable via modification of preparation conditions.

Mesoporous silicas through a dual-templating approach have attracted much attention because of some special hollow-shell structures might be obtained by this way.
The hollow structures find applications in chromatography, nanocatalysts, bimolecular encapsulation, gene delivery, and drug storage and release due to their unique properties of large cavity, low density, high pore volume, and permeable mesoporous walls [13]. Generally, polymer beads, air bubbles, oil droplets, colloids, or vesicles have been used to control the sizes of hollow cores, while amphiphile self-assemblies have been used to control the diameters of the pores in the shells [14-18]. However, the exact structural nature of mesoporous silica through a dual-templating approach and their formation manner under different synthesis conditions remain unclear so far. Herein, mesoporous silicas using a chiral cationic lowmolecular-weight amphiphile and organic solvents such as toluene, cyclohexane, tetrachlorocarbon, and tetrahydrofuran through a dual-templating approach were described. Nanospheres and nanoflakes had been obtained by tuning the kind and amount of the organic solvents precisely.

\section{Experimental}

2.1. Chemicals and Reagents. Tetraethyl orthosilicate (TEOS) was purchased from Aldrich. Toluene, cyclohexane, tetrahydrofuran, and tetrachlorocarbon were purchased from Sinopharm Chemical Reagent Co., Ltd. 


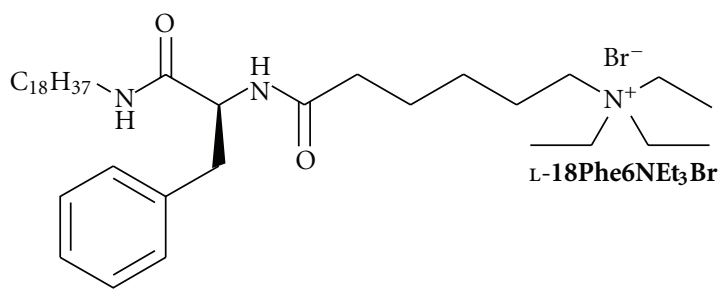

FIgURE 1: Molecular structure of the compound L-18Phe6 $\mathrm{NEt}_{3} \mathrm{Br}$.

2.2. Characterization. FT-IR spectrum was taken on a Nicolet 6700 spectrometer, using $\mathrm{KBr}$ pellets of the solids. The ${ }^{1} \mathrm{H}$ NMR spectrum was recorded on a Varian NMR 400 spectrometer in DMSO- $d^{6}$ solutions using TMS as an internal standard. Elemental analysis was performed on a Perkin Elmer series II CHNS/O analyzer 2400. Circular dichroism (CD) and UV-Vis spectra were measured on an AVIV 410 spectrophotometer. TEM images were obtained using a TecnaiG220 microscope operating at $200 \mathrm{kV}$. FESEM images were taken on a Hitachi S-4800 microscope operating at $15 \mathrm{kV}$. Before taking the FESEM images, the sample surface was coated with platinum. Specific surface area and pore-size distribution were determined by the BrunauerEmmett-Teller (BET) and the Barrett-Joyner-Halenda (BJH) methods using $\mathrm{N}_{2}$ desorption isotherms measured by a Micrometeritics ASAP $2020 \mathrm{M}+\mathrm{C}$ instrument at $77 \mathrm{~K}$. Small angle X-ray diffraction (SAXRD) pattern was taken on an $\mathrm{X}^{\prime}$ Pert-Pro MPD X-ray diffractometer using $\mathrm{Cu} \mathrm{K \alpha}$ radiation.

\subsection{Preparation of Mesoporous Silica Nanostructures}

2.3.1. Characterization of $\mathrm{L}-18 \mathrm{Phe} 6 \mathrm{NEt}_{3} \mathrm{Br}$. Compound L-18Phe6 $\mathrm{NEt}_{3} \mathrm{Br}$ (Figure 1), which is composed of 1 phenylalanine, was synthesized according to the literature [19]. FT-IR (KBr): $3294 \mathrm{~cm}^{-1}\left(\nu_{\mathrm{N}-\mathrm{H}}\right.$, amide A), $1651 \mathrm{~cm}^{-1}$ $\left(\nu_{\mathrm{C}=\mathrm{O}}\right.$, amide I), $1543 \mathrm{~cm}^{-1}\left(\nu_{\mathrm{N}-\mathrm{H}}\right.$, amide II). ${ }^{1} \mathrm{H}$ NMR $\left(300 \mathrm{MHz}, \mathrm{DMSO}-d^{6}, \mathrm{TMS}, 25^{\circ} \mathrm{C}\right): \delta=0.83(t, J=6.4 \mathrm{~Hz}$, $\left.3 \mathrm{H} ; \mathrm{CH}_{3}\right), 1.15\left(d, J=7.2 \mathrm{~Hz}, 3 \mathrm{H} ; \mathrm{CHCH}_{3}\right), 1.13-1.41$ (br, 30 $\overline{\mathrm{H}}$; alkyl), $1.69\left(\mathrm{~m}, 2 \mathrm{H}\right.$; $\left.\mathrm{CONHCH}_{2} \mathrm{CH}_{2}\right), 1.99-2.08$ (m, 2H; $\left.\mathrm{CH}_{2} \mathrm{CH}_{2} \mathrm{CONH}\right), 2.67-2.75\left(m, 2 \mathrm{H} ; \mathrm{CH}_{2} \mathrm{CONH}\right)$, 2.87-3.01 (m, 2H; $\left.\mathrm{CONHCH}_{2}\right), 4.35(q, J=\overline{7.8} \mathrm{~Hz}, 1 \mathrm{H}$; $\left.\mathrm{PhCH}_{2} \mathrm{CH}\right), 4.48-4.65\left(t, J=7.2 \mathrm{~Hz}, 2 \mathrm{H} ; \mathrm{PhCH}_{2}\right), 7.21(m$, $1 \mathrm{H} ; 1-\mathrm{Ph} \underline{\mathrm{H}}), 7.12(t, J=7.5 \mathrm{~Hz}, 1 \mathrm{H} ; 3-\mathrm{Ph} \underline{\mathrm{H}}), 7.08(t, J=$ $5.4 \mathrm{~Hz}, 1 \mathrm{H} ; 2-\mathrm{Ph} \underline{\mathrm{H}}), 7.88\left(t, J=9.1 \mathrm{~Hz}, 1 \mathrm{H} ; \mathrm{CON}^{\mathrm{HCH}}{ }_{2}\right)$, $7.99(d, J=7.8 \mathrm{~Hz}, 1 \mathrm{H} ; \mathrm{CON} \underline{\mathrm{HCH}})$. Elemental analysis calcd(\%): C, 67.41; H, 10.44; N, 6.05. Found: C, 65.63; H, $9.86 ; \mathrm{N}, 5.91$.

2.3.2. Synthetic Procedure for the Mesoporous Silica So. A typical synthetic procedure was shown as follows: $200 \mathrm{mg}$ $(0.31 \mathrm{mmol})$ of $\mathrm{L}-18 \mathrm{Phe} \mathrm{NEt}_{3} \mathrm{Br}$ was dissolved in $50.0 \mathrm{~mL}$ of deionized water. Then, $0.35 \mathrm{~mL}$ of aqueous $\mathrm{NaOH}(2.0 \mathrm{M})$ solution and $0.5 \mathrm{~mL}$ of toluene were added at the stirring rate of $1500 \mathrm{rpm}$ at $80^{\circ} \mathrm{C}$. $3.0 \mathrm{~min}$ later, $1.0 \mathrm{~mL}(4.5 \mathrm{mmol})$ of TEOS was dropped into the mixtures under stirring. The reaction mixture was kept at that temperature for $2.0 \mathrm{hrs}$. The resultant white precipitate was filtered and dried to yield asprepared mesoporous silica. L-18Phe6 $\mathrm{NEt}_{3} \mathrm{Br}$ was removed by extracting with a mixture of $80 \mathrm{~mL}$ of methanol and $10 \mathrm{~mL}$ of $36 \mathrm{wt} \%$ aqueous $\mathrm{HCl}$ solution. Finally, calcination was preformed at $550^{\circ} \mathrm{C}$ for $5.0 \mathrm{~h}$ under aerobic conditions, with a ramp rate of $1.0^{\circ} \mathrm{C} \mathrm{min}^{-1}$.

2.3.3. Synthetic Procedure for the Mesoporous Silicas $\mathbf{S 1}$ Series. Toluene was added into the reaction mixture. The toluene/water volume ratio was varied $(0.01,0.02,0.04)$ while keeping the other reaction conditions constant. The obtained samples were named as S1-1, S1-2, and S1-3, respectively.

2.3.4. Synthetic Procedure for the Mesoporous Silica S2. The synthetic procedure is similar as that for S0, except for the addition of $1.0 \mathrm{~mL}$ of cyclohexane and that the reaction temperature is $65^{\circ} \mathrm{C}$.

2.3.5. Synthetic Procedure for the Mesoporous Silica S3. The synthetic procedure is similar as that for S0, except for the addition of $1.5 \mathrm{~mL}$ of tetrachlorocarbon and that the reaction temperature is $65^{\circ} \mathrm{C}$.

2.3.6. Synthetic Procedure for the Mesoporous Silica S4. The synthetic procedure is similar as that for S0, except for the addition of $1.0 \mathrm{~mL}$ of THF and that the reaction temperature is $65^{\circ} \mathrm{C}$.

\section{Results and Discussion}

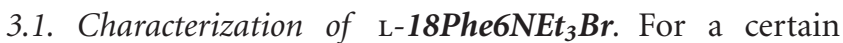
amphiphile, it can self-assemble into supramolecular structures through $\mathrm{H}$-bondings, solvophobic associations, cationic-anionic and $\pi-\pi$ interactions, and the selfassembly behaviors are sensitive to solvents, $\mathrm{pH}$ values, and temperatures $[20,21]$. Compound $\mathrm{L}-18 \mathrm{Phe} \mathbf{N E t}{ }_{3} \mathrm{Br}$ causes viscous liquid in deionized water with a concentration of $10 \mathrm{~g} \mathrm{~L}^{-1}$ at $25^{\circ} \mathrm{C}$, and physical gels in cyclohexane, ethanol, and 1,4-dioxane, and shows low solubility in toluene, THF, and acetone. The CD and UV-Vis spectra of its aqueous solutions at a concentration of $10 \mathrm{~g} \mathrm{~L}^{-1}$ are shown in Figure 2. The UV-Vis spectrum shows an absorption band at $259 \mathrm{~nm}$ attributed to the aromatic rings. A positive signal at $225 \mathrm{~nm}$ and a negative signal at $221 \mathrm{~nm}$ in the CD spectrum 


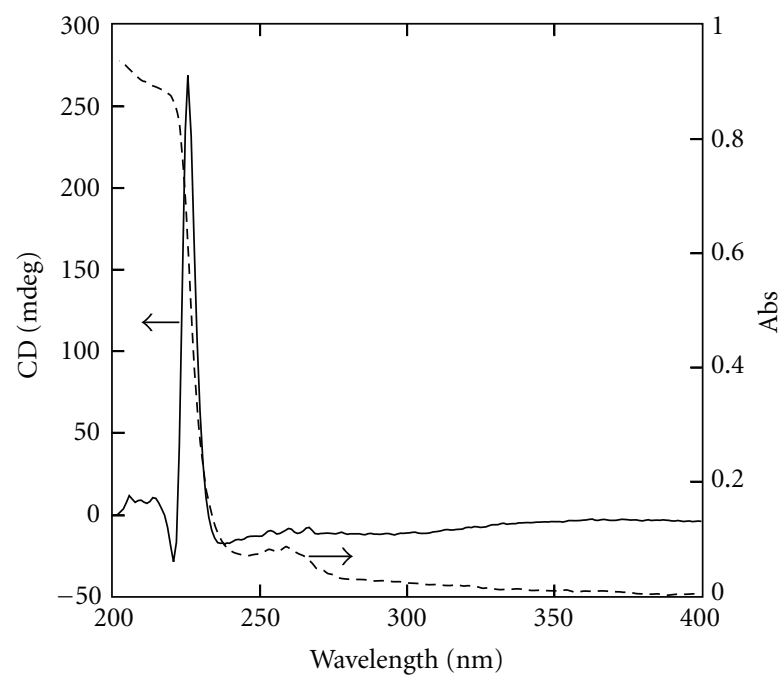

FIGURE 2: CD and UV-Vis spectra of the compound L-18Phe6NEt 3 Br.

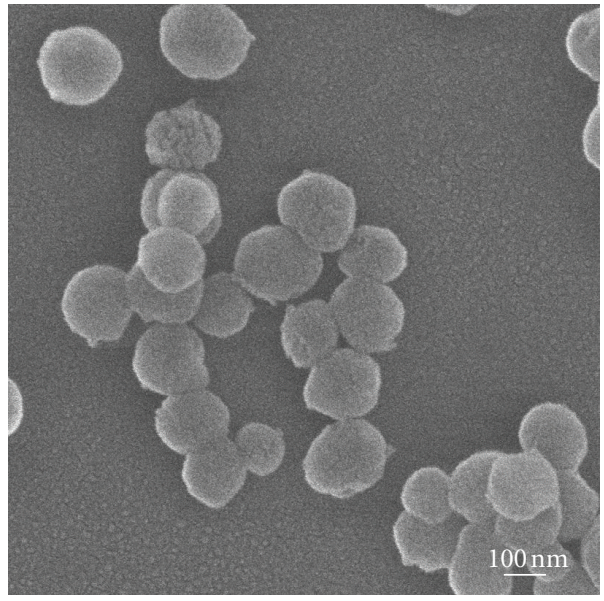

(a)

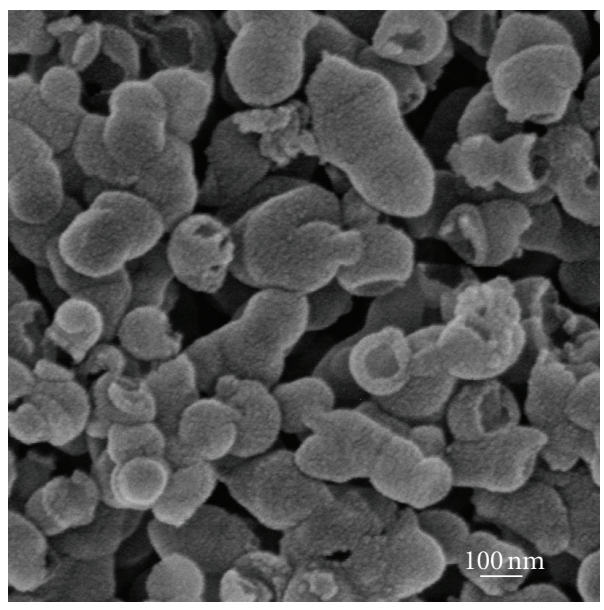

(c)

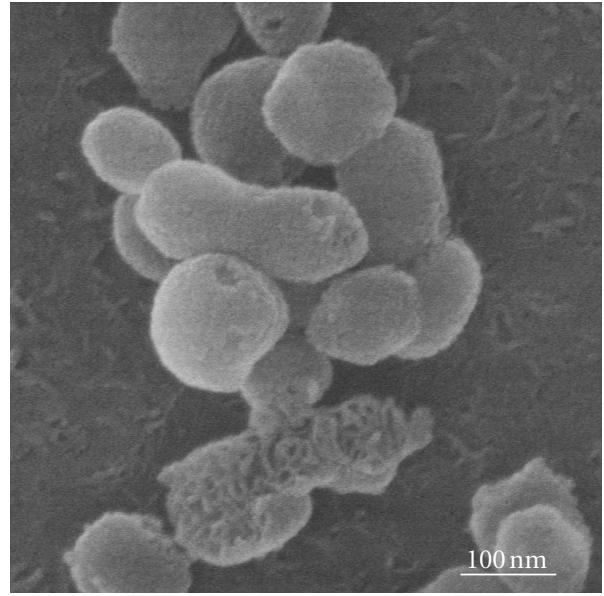

(b)

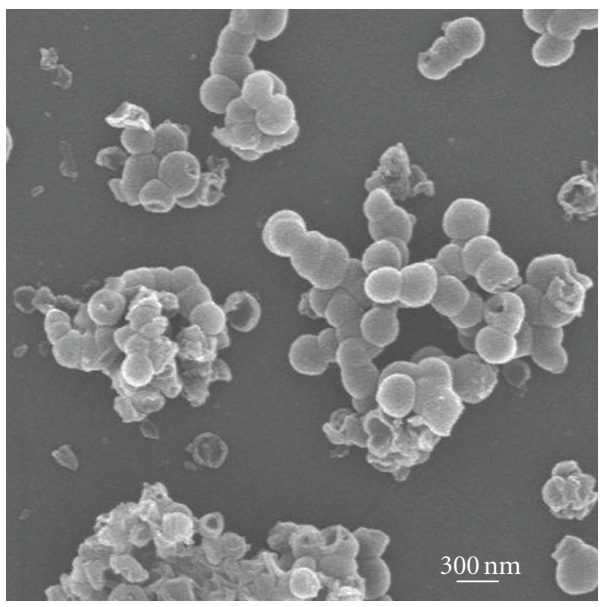

(d)

FIGURE 3: FESEM images of the mesoporous silica nanostructures S0 (a) and S1 prepared in the mixtures of toluene and water (S1-1 (b); S1-2 (c); S1-3 (d)). 


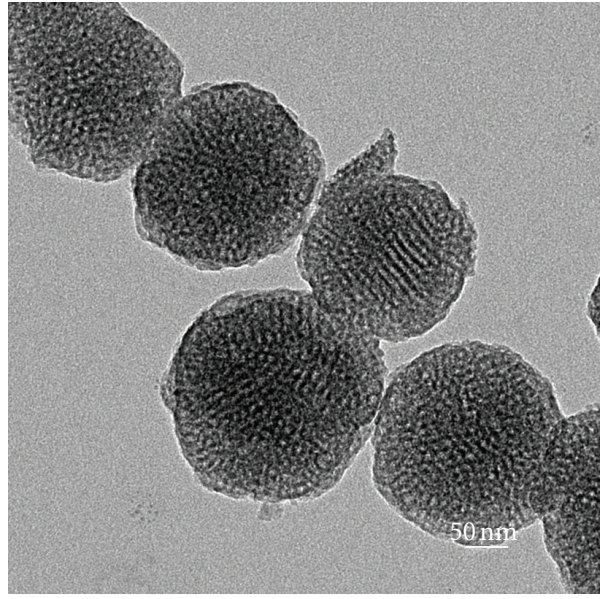

(a)

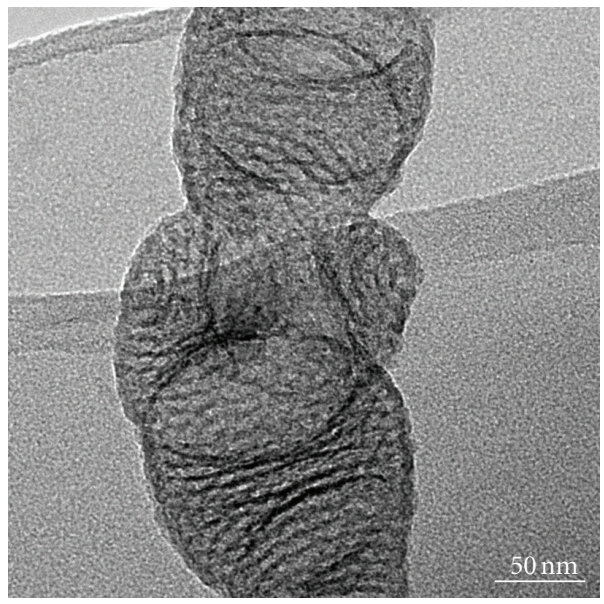

(c)

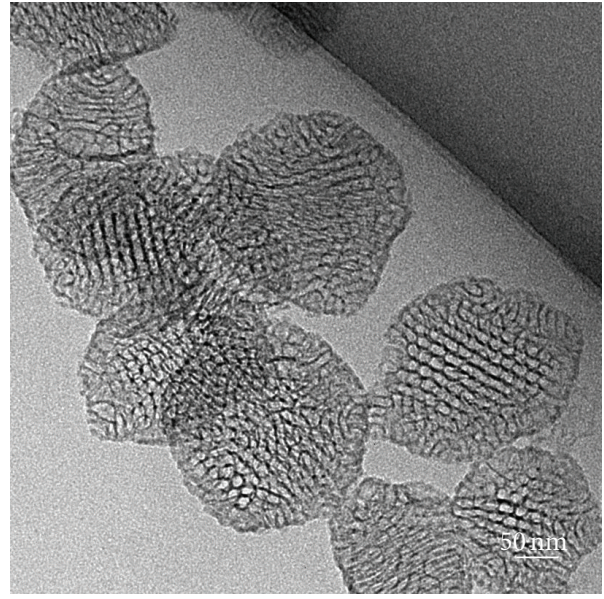

(b)

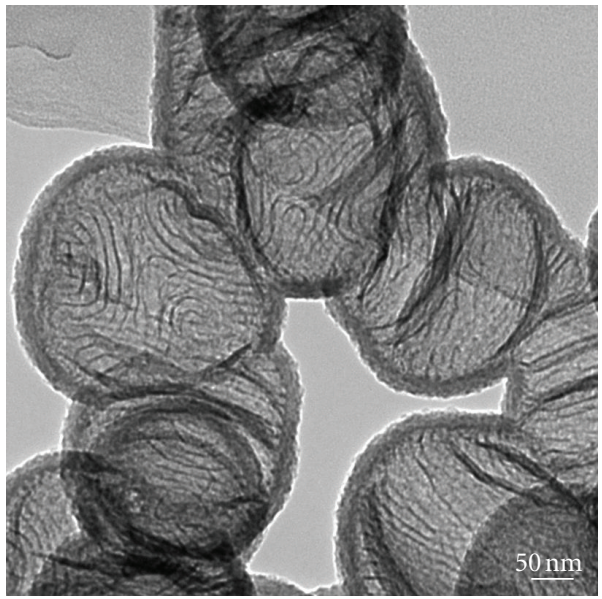

(d)

FIgURE 4: TEM images of the mesoporous silica nanostructures S0 (a), S1-1 (b), S1-2 (c), and S1-3 (d).

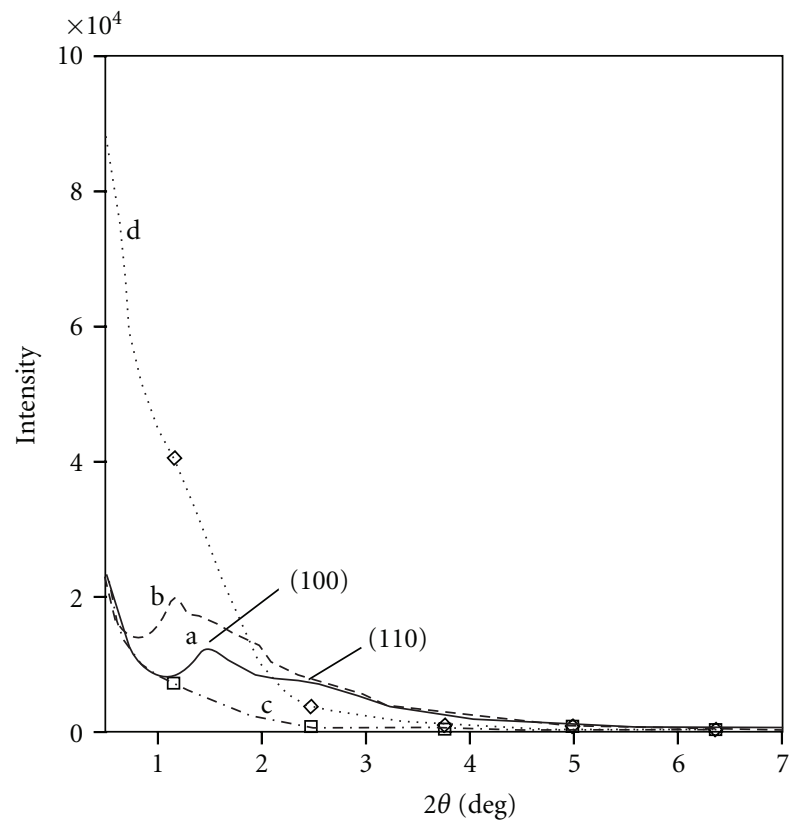

FIGURE 5: SAXRD patterns of the mesoporous silica nanostructures S0 (a), S1-1 (b), S1-2 (c), and S1-3 (d). 


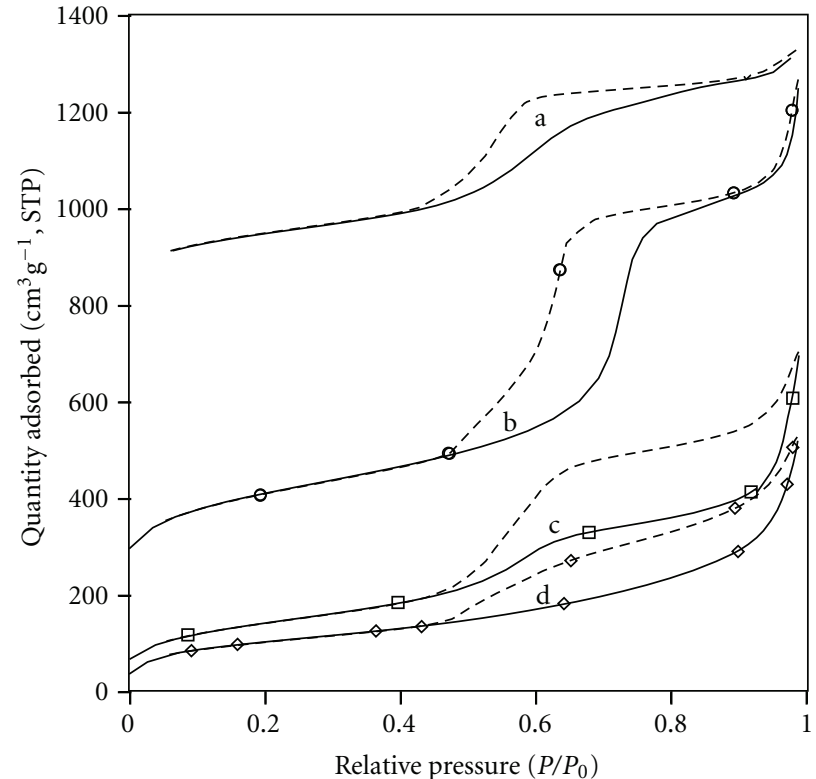

(A)

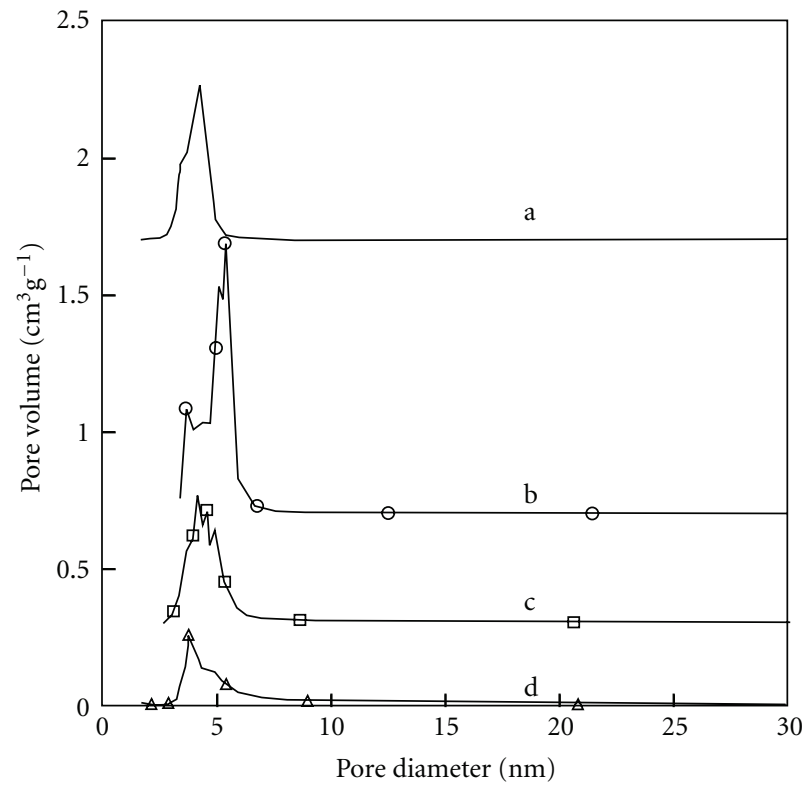

(B)

FIGURE 6: $\mathrm{N}_{2}$ adsorption-desorption Sorption isotherms (A) and BJH pore size distribution plots calculated from the desorption branch (B) of the mesoporous silica nanostructures S0 (a), S1-1 (b), S1-2 (c), and S1-3 (d).

are identified, indicating a right-handed staking among the chiral molecules.

\subsection{Characterization of Mesoporous Silicas SO and $\mathbf{S 1 .}$} The FESEM images of them were shown in Figure 3. For S0, nanospheres with diameters of 80-150 nm were identified (Figure 3(a)). When toluene was added into the reaction mixture at the toluene/water volume ratio of 0.01, 0.02, and 0.04, samples S1-1, S1-2, and S1-3 were obtained, respectively. The FESEM images of them were shown in Figures 3(b) to 3(d). It was found that the toluene/water volume ratio played an important role in controlling the morphologies of the mesoporous silicas. For S1-1, nanospheres with sponge-like mesopores inside were identified (Figure 3(b)). The diameters of the nanospheres are about $80-150 \mathrm{~nm}$. Fine toluene droplets were proposed as the templates for the sponge-like mesopores. For S12, hollow nanostructures with diameters about $80-300 \mathrm{~nm}$ were identified (Figure 3(c)). The fine toluene droplets were proposed to merge together and then acted as templates for the hollow nanostructures. The structure of S1-3 is similar as S1-2. Hollow silica nanospheres with a large inner cavity of 150-200 nm were identified (Figure 3(d)). Namely, with increasing the toluene/water volume ratio, the morphologies of the silicas changed from solid spheres to hollow spheres.

The TEM images of S0 and S1 series were shown in Figure 4. For S0, partially hexagonally organized mesopores were identified (Figure 4(a)). It is difficult to discern whether the mesopores on the surface of spheres are close or open. These nanospheres are not hollow. For S1-1, the mesopores seem to be also hexagonally organized (Figure $4(\mathrm{~b})$ ). The pore diameter is estimated to be $5-8 \mathrm{~nm}$. For S1-2, hollow silica nanococoons with coiled pore channels within the shells were identified (Figure 4(c)). The linkage of the nanococoons induced the formation of the chambers. TEM image of S1-3 samples confirmed the hollow spherical morphology (Figure 4(d)). The thickness of the shell is around $10 \mathrm{~nm}$, and the circular pore channels can be clearly discerned within the shells (Figure $4(\mathrm{~d})$ ). The results shown in Figure 4 indicated that the silicas changed from spheres with hexagonally arranged pore channels to hollow spheres with single-layer of coiled ones in the walls, with increasing the toluene/water volume ratio.

The SAXRD patterns of the mesoporous silicas S0, S11, S1-2, and S1-3 are shown in Figure 5. For S0, two wellresolved diffraction peaks at $2 \theta$ of $1.5^{\circ}$ and $2.4^{\circ}$ are identified, indicating a two-dimensional hexagonal symmetry, which consists with TEM images shown in Figure 4(a). For S1-1, only one broad diffraction peak at $2 \theta$ of $1.2^{\circ}$ is identified, which indicates that this material does not exhibit a long range order. The $d$-spacing calculated from the diffraction peak is $3.8 \mathrm{~nm}$. For S1-2 and S1-3, no sharp diffraction peaks are identified, indicating a less ordered mesostructure, which consist with the TEM images shown in Figures 4(c) and 4(d). The addition of toluene destroyed the ordered arrangement the mesopores.

The mesoporosity of these samples was characterized using a nitrogen sorption analysis. They exhibit type-IV-like isotherms (Figure 6(A)). It is noticeable that the isotherms of S0, S1-1, and S1-2 show two sharp capillary-condensation steps in the relative pressure range of $0.4-1.0$, indicating the existence of two types narrow mesopore size distributions. The capillary-condensation step at ca. 0.42 in relative pressure is an indication of typical uniform mesopores in the shell, while that occurred at a relative pressure of 0.9 is probably a result of the hollow cores and voids among the 


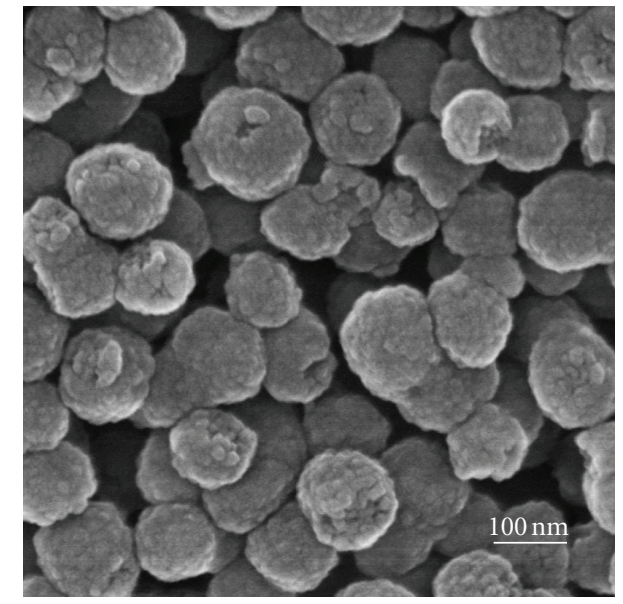

(a)

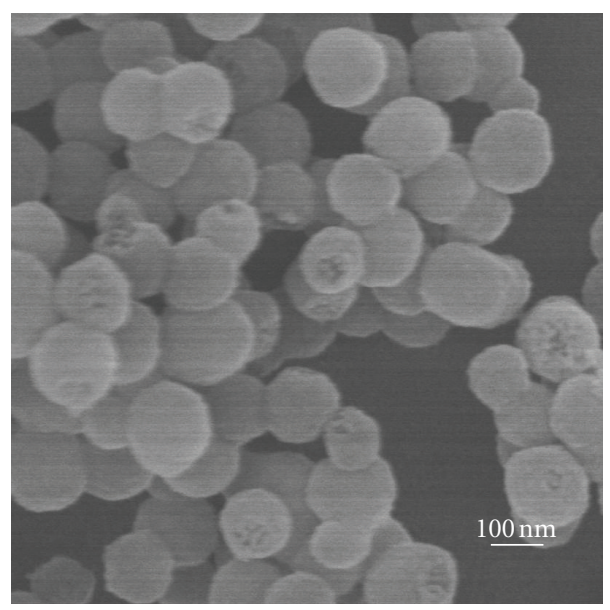

(c)

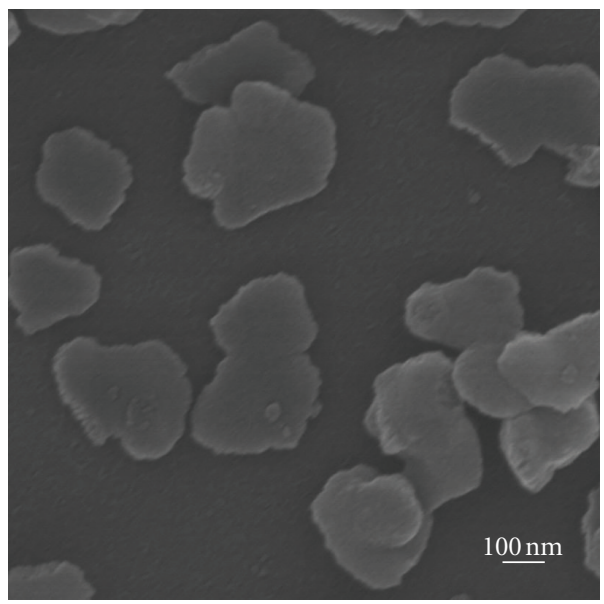

(e)

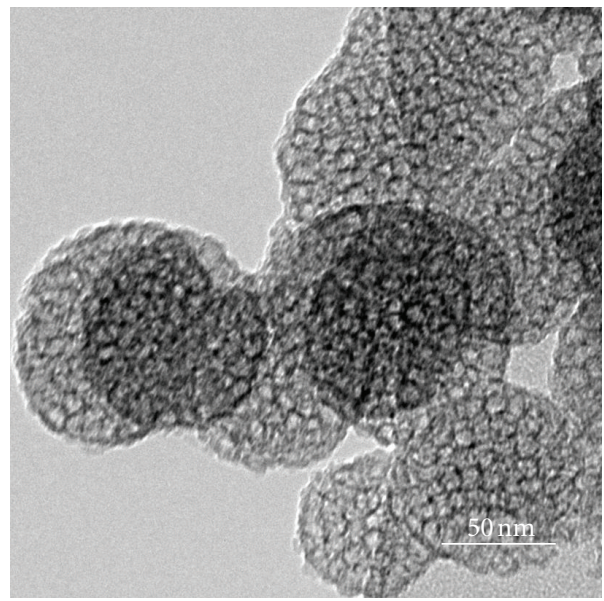

(b)

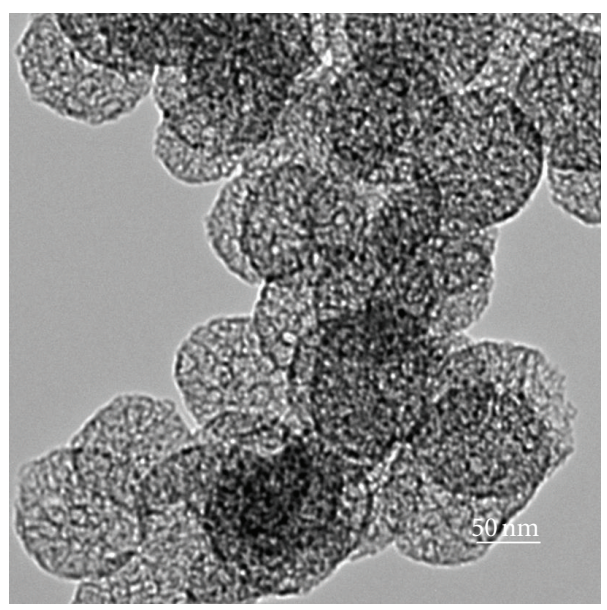

(d)

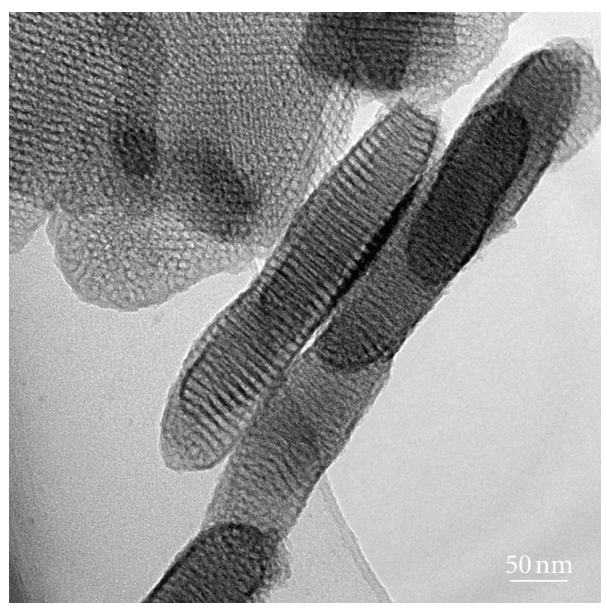

(f)

Figure 7: FESEM (a, c, and e) and TEM (b, d, and f) images of the mesoporous silica nanostructures S2 (a and b), S3 (c and d), and S4 (e and $\mathrm{f})$. 
particles. For S0, S1-1, S1-2, and S1-3, the BET surface areas are $540,752,507$, and $369 \mathrm{~m}^{2} / \mathrm{g}$, and the BJH pore diameters determined from the desorption branch are 4.71, 5.3, 4.1, and $3.8 \mathrm{~nm}$, respectively (Figure 6(B)). The change of surface area is due to the formation of larger hollow cavity inside the nanospheres.

It is reported that the addition of organic dopants can decrease the critical micelle concentration of surfactant and enhance the formation of rod-like or worm-like micelles. Lamellar structures are feasible to be formed by increasing the molarity of organic dopants [22]. Toluene, as a kind of water-immiscible organic dopant, can construct vesicles together with self-assembled amphiphile amino acid derivatives to form a hollow cavity structure through a vesicle templating process. Subsequently, amphiphile compound L$18 \mathrm{Phe} \mathrm{NEt}_{3} \mathrm{Br}$ with a strong positively charged $-\mathrm{N}^{+}$may interact with negatively charged silica species to build mesostructured walls around the vesicles by a liquid-crystal templating process [23], which determines the final structure of silica hollow spheres. When the addition amount of toluene is small, the fine vesicles destroy the regularity of hexagonal mesopores; therefore, some sponge-like mesopores appear inside silica nanospheres S1-1 (Figure 3(b)). When more toluene is added to the reaction mixture, larger oil droplets may be formed due to phase separation and then act as hard template for the nanospheres. The amphiphile compound molecules act as soft template, accumulating on the oil-water interface, self-assembling, and interacting with silica species. When the oil droplet is removed, a hollowshell structure forms. Meanwhile, the circular pore channels are formed on the shell after getting rid of the amphiphile compound (Figures 3(c) and 3(d)).

3.3. Characterization of Silicas S2, S3, and S4 Prepared Using Cyclohexane, Tetrachlorocarbon, and Tetrahydrofuran as the Organic Solvents, Respectively. Since the addition of organic solvents strongly affect the morphologies and pore architectures of mesoporous silicas [24], samples prepared in the mixture of water and other organic solvents as cyclohexane, tetrachlorocarbon, and THF are obtained and studied, which were named as S2, S3, and S4, respectively. For S2, the obtained products are nanospheres about 50 $150 \mathrm{~nm}$ in diameter (Figure 7(a)). Mesopores uniformly distribute within the spheres (Figure 7(b)). S3 is similar as S2 (Figures 7(c) and 7(d)). However, the arrangement of the mesopores is not ordered. Both samples S2 and S3 are not hollow. Unlike above, four sphere-like samples S0-S3, S4, are flake-like (Figure 7(e)). The diameters and the thickness of the flakes are about $100-200$ and $50 \mathrm{~nm}$, respectively. The hexagonally arranged are parallel to the short axes of the nanoflakes with a pore diameter of about $6.0 \mathrm{~nm}$ (Figure 7(f)). THF is a water-miscible polar solvent, while cyclohexanse and tetrachlorocarbon, are immiscible with water. The formation of these fine mesoporous silica flakes might be explained by the fact that $\mathrm{L}-18 \mathrm{Phe} 6 \mathrm{NEt}_{3} \mathrm{Br}$ exhibits high solubility in THF. Then, $\mathrm{L}-\mathbf{1 8} \mathrm{Phe} 6 \mathrm{Net}_{3} \mathrm{Br}$ acted as a surfactant in the mixture of water and THF. Finally, the hexagonally arranged pore architecture was obtained. Such nanoflakes with perpendicular pores have been also prepared through other approach [25]. These ordered perpendicular pore channels are expected to have potential applications in many fields such as separation membranes and hard templates for nanorods or nanofibers.

\section{Summary}

Mesoporous silica nanospheres, hollow nanospheres, and nanoflakes were prepared using a chiral cationic lowmolecular-weight amphiphile and organic dopants, such as toluene, cyclohexane, tetrachlorocarbon, and THF through a dual-templating approach. Since the morphologies and pore architectures of mesoporous silicas could to be manipulated by adding organic dopants, more interesting structures are proposed to obtained through this dual-templating approach.

\section{Acknowledgments}

This work was supported by Program of Innovative Research Team of Soochow University, National Natural Science Foundation of China (no. 211040503 and 21074086), and Natural Science Foundation of Jiangsu Province (no. SBK201121829).

\section{References}

[1] H.-P. Lin and C.-Y. Mou, "Structural and morphological control of cationic surfactant-templated mesoporous silica," Accounts of Chemical Research, vol. 35, no. 11, pp. 927-935, 2002.

[2] M. E. Davis, "Ordered porous materials for emerging applications," Nature, vol. 417, no. 6891, pp. 813-821, 2002.

[3] H. P. Hentze, S. R. Raghavan, C. A. McKelvey, and E. W. Kaler, "Silica hollow spheres by templating of catanionic vesicles," Langmuir, vol. 19, no. 4, pp. 1069-1074, 2003.

[4] W. Li, X. Sha, W. Dong, and Z. Wang, "Synthesis of stable hollow silica microspheres with mesoporous shell in nonionic W/O emulsion," Chemical Communications, no. 20, pp. 24342435, 2002.

[5] L. Li, E. S.G. Choo, X. Tang, J. Ding, and J. Xue, "A facile one-step route to synthesize cage-like silica hollow spheres loaded with superparamagnetic iron oxide nanoparticles in their shells," Chemical Communications, no. 8, pp. 938-940, 2009.

[6] A. Lind, B. Spliethoff, and M. Lindén, "Unusual, vesiclelike patterned, mesoscopically ordered silica," Chemistry of Materials, vol. 15, no. 3, pp. 813-818, 2003.

[7] M. Ogawa, "Formation of novel oriented transparent films of layered silica-surfactant nanocomposites," Journal of the American Chemical Society, vol. 116, no. 17, pp. 7941-7942, 1994.

[8] Y. Lu, R. Ganguli, C. A. Drewien et al., "Continuous formation of supported cubic and hexagonal mesoporous films by sol-gel dip-coating," Nature, vol. 389, no. 6649, pp. 364-368, 1997.

[9] H. Yang, G. Vovk, N. Coombs, I. Sokolov, and G. A. Ozin, "Synthesis of mesoporous silica spheres under quiescent aqueous acidic conditions," Journal of Materials Chemistry, vol. 8, no. 3, pp. 743-750, 1998. 
[10] J. Wang, C. -K. Tsung, R. C. Hayward, Y. Wu, and G. D. Stucky, "Single-crystal mesoporous silica ribbons," Angewandte Chemie - International Edition, vol. 44, no. 2, pp. 332336, 2004.

[11] H. P. Lin and C. Y. Mou, "'Tubules-within-a-tubule' hierarchical order of mesoporous molecular sieves in MCM-41," Science, vol. 273, no. 5276, pp. 765-768, 1996.

[12] P. J. Bruinsma, A. Y. Kim, J. Liu, and S. Baskaran, "Mesoporous silica synthesized by solvent evaporation: spun fibers and spray-dried hollow spheres," Chemistry of Materials, vol. 9, no. 11, pp. 2507-2512, 1997.

[13] F. Caruso, "Hollow capsule processing through colloidal templating and self-assembly," Chemistry - A European Journal, vol. 6, no. 3, pp. 413-419, 2000.

[14] K. W. Gallis, J. T. Araujo, K. J. Duff, J. G. Moore, and C. C. Landry, "The use of mesoporous silica in liquid chromatography," Advanced Materials, vol. 11, no. 17, pp. 1452-1455, 1999.

[15] P. M. Arnal, M. Comotti, and F. Schüth, "High-temperaturestable catalysts by hollow sphere encapsulation," Angewandte Chemie - International Edition, vol. 45, no. 48, pp. 8224-8227, 2006.

[16] J. Kim, J. Lee, H. B. Na et al., "A magnetically separable, highly stable enzyme system based on nanocomposites of enzymes and magnetic nanoparticles shipped in hierarchically ordered, mesocellular, mesoporous silica," Small, vol. 1, no. 12, pp. 1203-1207, 2005.

[17] J. F. Chen, H. M. Ding, J. X. Wang, and L. Shao, "Preparation and characterization of porous hollow silica nanoparticles for drug delivery application," Biomaterials, vol. 25, no. 4, pp. 723-727, 2004.

[18] Y. Zhu, J. Shi, W. Shen et al., "Stimuli-responsive controlled drug release from a hollow mesoporous silica sphere/polyelectrolyte multilayer core-shell structure," Angewandte Chemie - International Edition, vol. 44, no. 32, pp. 5083-5087, 2005.

[19] B. Li, Y. Chen, H. Zhao et al., "From branched self-assemblies to branched mesoporous silica nanoribbons," Chemical Communications, no. 47, pp. 6366-6368, 2008.

[20] J. Gao, H. Wang, L. Wang, J. Wang, D. Kong, and Z. Yang, "Enzyme promotes the hydrogelation from a hydrophobic small molecule," Journal of the American Chemical Society, vol. 131, no. 32, pp. 11286-11287, 2009.

[21] J. Wang, Z. Wang, J. Gao et al., "Incorporation of supramolecular hydrogels into agarose hydrogels-a potential drug delivery carrier," Journal of Materials Chemistry, vol. 19, no. 42, pp. 7892-7896, 2009.

[22] K. J. C. Van Bommel, A. Friggeri, and S. Shinkai, "Organic templates for the generation of inorganic materials," Angewandte Chemie - International Edition, vol. 42, no. 9, pp. 980 999, 2003.

[23] H. Djojoputro, X. F. Zhou, S. Z. Qiao, L. Z. Wang, C. Z. Yu, and G. Q. Lu, "Periodic mesoporous organosilica hollow spheres with tunable wall thickness," Journal of the American Chemical Society, vol. 128, no. 19, pp. 6320-6321, 2006.

[24] Y. Yang, M. Suzuki, S. Owa, H. Shirai, and K. Hanabusa, "Preparation of helical nanostructures using chiral cationic surfactants," Chemical Communications, no. 35, pp. 4462 4464, 2005.

[25] Z. Yan, B. Li, S. Wang et al., "Preparation of Mesoporous Silica Nanoribbons and Nanoflakes with Short Pore Channels Using a Chiral Amphiphile," Journal of Nanoscience and Nanotechnology, vol. 10, no. 10, pp. 1-7, 2010. 

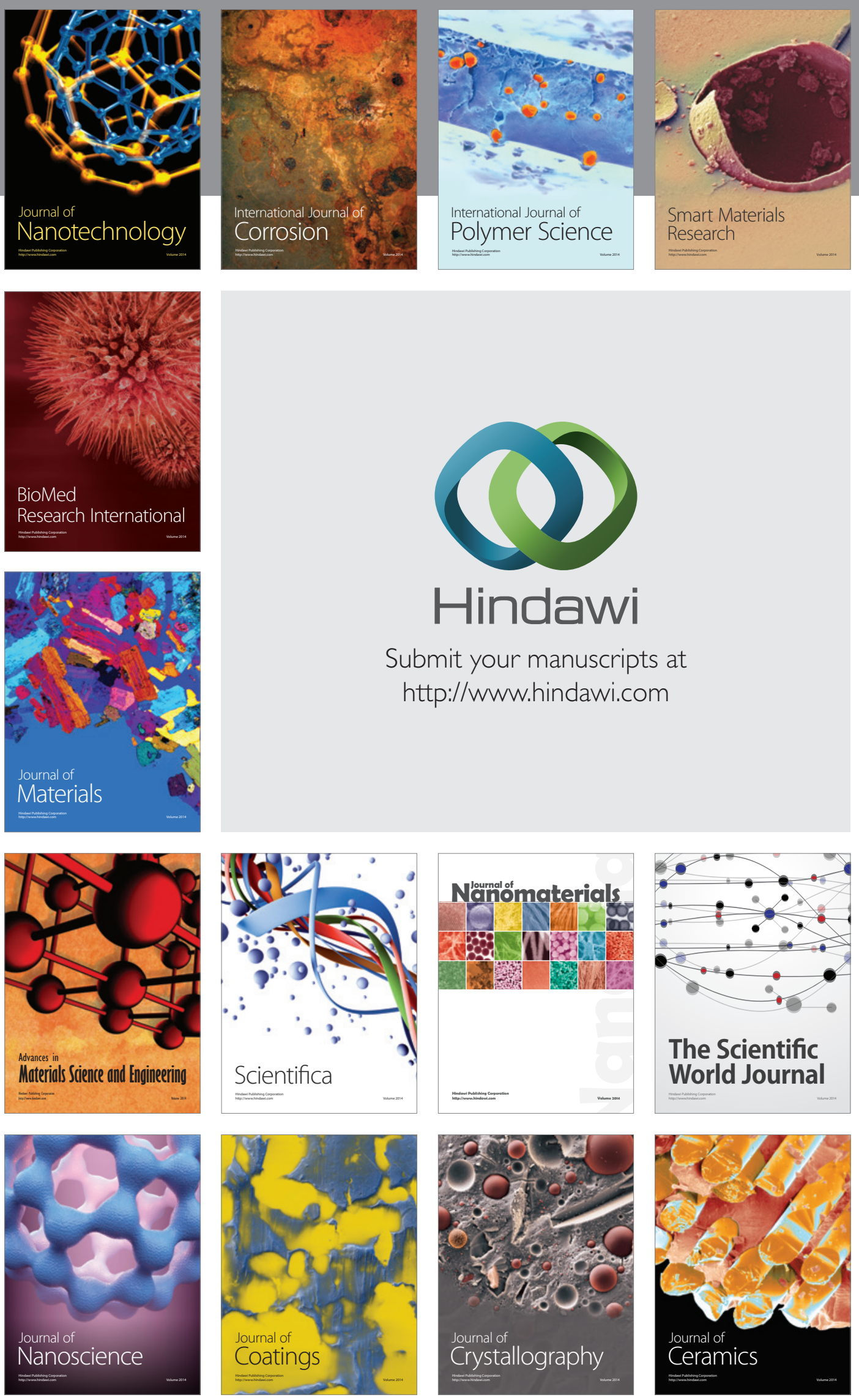

The Scientific World Journal

Submit your manuscripts at

http://www.hindawi.com

\section{World Journal}

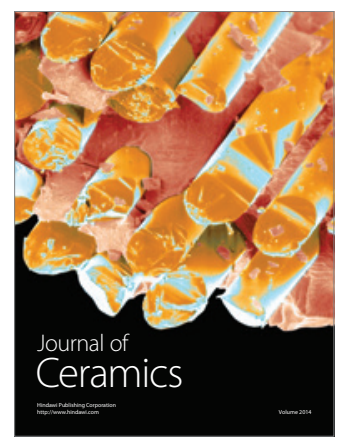

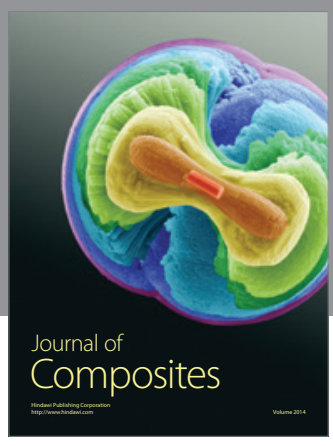
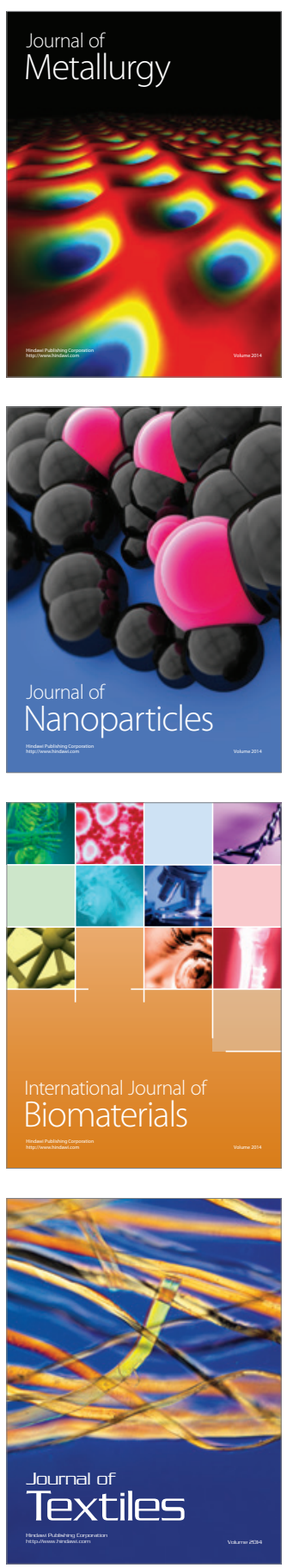